\title{
ESTUDO DE VIABILIDADE DA CRIAÇÃO DE RETRIBUIÇÃO PECUNIÁRIA DE COMPENSAÇÃO ORGÂNICA AOS MERGULHADORES DO CORPO DE BOMBEIROS MILITAR DO ESTADO DE MATO GROSSO
}

Heitor Alves de Souza ${ }^{1}$

\section{RESUMO}

O artigo examina a atividade de mergulho no Corpo de Bombeiros Militar do Estado de Mato Grosso procurando verificar aspectos legais e técnicos que tratam do adicional de compensação orgânica para a atividade. Parte do pressuposto de que os mergulhadores profissionais da corporação estão expostos a riscos e substâncias danosas sem recebimento de vantagem pecuniária concedida a outros servidores civis e militares que habitualmente trabalham em locais insalubres e/ou periculosos. Adota abordagem qualitativa, de cunho exploratório, revisa literatura sobre o tema, investiga a questão em outras Corporações de Bombeiros Militares no país e utiliza entrevista com o escopo de verificar a viabilidade da criação de retribuição pecuniária de compensação orgânica aos bombeiros militares mergulhadores. À luz das discussões entabuladas, conclui que a atividade de busca e recuperação subaquática do Corpo de Bombeiros Militar de Mato Grosso é atividade insalubre e carece de regulamentação para o devido e necessário recebimento da parcela remuneratória assegurada em diversos corpos legais civis e militares.

Palavras-chave: Compensação orgânica; Insalubridade; Mergulho; Bombeiros.

\footnotetext{
${ }^{1}$ Major Bombeiro Militar do Estado de Mato Grosso. Graduado em Gestão de Riscos Coletivos pelo Instituto de Ensino de Segurança Pública do Pará (IESP), pós-graduado em Gerenciamento de Segurança Pública no Curso de Aperfeiçoamento de Oficiais pela Superintendência da Academia de Segurança Pública de Goiás, mergulhador de resgate do Corpo de Bombeiros Militar de Mato Grosso. E-mail: heitor_bm@hotmail.com.
} 


\title{
STUDY FOR CREATION OF PECUNIARY COMPENSATION TO DIVERS IN THE FIRE DEPARTMENT OF THE STATE OF MATO GROSSO IN BRAZIL
}

\begin{abstract}
The article examines the diving activity in the Mato Grosso Fire Department seeking to verify legal and technical aspects that deal with the additional organic compensation for the activity. It assumes that professional divers in the corporation are exposed to risks and harmful substances without receiving a pecuniary advantage granted to other civilian and military servants who usually work in unhealthy and / or dangerous locations. It adopts a qualitative approach, of an exploratory nature, reviews literature on the subject, investigates the issue in other Fire Departments in the country and uses an interview with the scope of verifying the feasibility of creating pecuniary compensation for organic compensation to divers military firefighters. In light of the ongoing discussions, he concludes that the underwater search and recovery activity of the Mato Grosso Fire Department is an unhealthy activity and lacks regulation for the due and necessary receipt of the remunerated portion insured in various civil and military legal documents.
\end{abstract}

Keywords: Orgânic compensation; Unhealthy; Dive; Firemen. 


\section{INTRODUÇÃO}

O serviço de mergulho é uma diligência comum nos Corpos de Bombeiros Militares do Brasil, que se utilizam da prática para resgatar afogados ou recuperar bens. A atividade exercida pelo serviço de busca e recuperação subaquática do Corpo de Bombeiros Militar do Estado de Mato Grosso (CBMMT) comporta situações de risco e exposição à substâncias que afetam o bem-estar físico, mental e psicológico dos mergulhadores. Não obstante, os militares que executam o serviço não recebem qualquer vantagem pecuniária, a título de adicional ou gratificação, que compense a sujeição a agentes agressivos à saúde e acidentes de mergulho.

Sob este prisma, o artigo procura verificar a viabilidade da criação e implementação de retribuição pecuniária de compensação orgânica aos mergulhadores do CBMMT que exercem atividades de busca e recuperação subaquática de cadáveres e objetos em ambiente hiperbárico nos rios, represas e lagos existentes nos domínios territoriais do Estado. Postula-se que tal ofício é uma atividade insalubre perante o ordenamento jurídico brasileiro e, como tal, a obtenção dessa vantagem pecuniária justifica-se pela condição desfavorável de trabalho a que os mergulhadores bombeiros militares de Mato Grosso estão sujeitos no exercício de atividade subaquática pela corporação.

A par disso, busca-se responder ao seguinte questionamento: há viabilidade de se criar e implementar retribuição pecuniária de compensação orgânica aos mergulhadores do CBMMT que executam as atividades de busca e recuperação subaquática? Consoante com esse fio norteador, o artigo aborda as características da atividade de mergulho no CBMMT, os aspectos jurídicos da insalubridade e do adicional de insalubridade na legislação brasileira, a compensação orgânica das Forças Armadas e as previsões existentes no ordenamento jurídico estadual. Em subsídio, apresenta pesquisa entabulada junto aos demais Corpos de Bombeiros Militares existentes no 
território nacional sobre as características da atividade e aspectos relevantes que tratam do adicional de compensação orgânica.

\section{CARACTERÍSTICAS DA ATIVIDADE DE MERGULHO NO CORPO DE BOMBEIROS MILITAR}

A atividade de mergulho é reconhecida pela Organização Internacional do Trabalho (OIT) como uma das profissões mais perigosas do mundo (COSTA, 2016). Isso ocorre por causa das adversidades e dos riscos que o meio hiperbárico (pressão ambiente superior à pressão atmosférica) impõe aos mergulhadores durante o desempenho de suas atividades, o que requer uma adaptação constante e a utilização de tecnologia avançada para que possam exercer sua função. Tais perigos e adversidades são potencializados quando se observa a atividade de mergulho realizada pelos bombeiros militares brasileiros na recuperação de cadáveres e objetos no meio subaquático: às características intrínsecas aos ambientes hiperbáricos somam-se as possibilidades de contaminação química e biológica.

Cumpre observar que o ambiente hiperbárico, por si só, já apresenta aos mergulhadores diversos fatores de risco que, quando não considerados corretamente, resultam em acidentes e doenças que podem levar a óbito. Esclareça-se que tal situação ocorre quando na ação de mergulhar passa-se da atmosfera terrestre, composta basicamente de ar, ao meio aquático com diferentes características físicas de pressão e densidade. Consequentemente, tais diferenças de pressão e densidade provocam alterações no aparelho circulatório e na dinâmica ventilatória dos mergulhadores (RAMOS, 2004).

Nessas circunstâncias, as mudanças de pressão a que os mergulhadores estão sujeitos no ambiente hiperbárico podem ocasionar diversos acidentes de mergulho causados pelos efeitos diretos e indiretos dessa variação hiperbárica. Sob este viés de análise, os efeitos diretos 
Revista Científica do Corpo de Bombeiros Militar de Pernambuco

Artigo Publicado no Vol.06 N.16 - Edição Especial 2020 - ISSN 2359-4829

Versão on-line disponível em: http://www.revistaflammae.com

resultam da ação mecânica da pressão sobre as células e espaços corporais como barotraumas, embolia traumática pelo ar, bloqueio reverso, dentre outros -, enquanto os indiretos são resultantes de alterações fisiológicas produzidas pelas pressões parciais dos gases absorvidos pelo organismo - como narcose, doença descompressiva, intoxicações, dentre outras (LEONARDI, 2017).

A título de ilustração dos efeitos da variação de pressão no meio subaquático, apresenta-se o Quadro 1.

Quadro 1 - Efeitos direitos e indiretos da pressão no organismo

\begin{tabular}{|l|l|}
\hline \multicolumn{1}{|c|}{ DIRETOS } & \multicolumn{1}{|c|}{ INDIRETOS } \\
\hline \multicolumn{1}{|c|}{ BAROTRAUMAS } & \multicolumn{1}{c|}{ BIOQUÍMICOS } \\
\hline Barotrauma de ouvido médio & Narcose pelo nitrogênio \\
Barotrauma de ouvido externo & Intoxicação pelo oxigênio \\
Barotrauma dos seios da face & Intoxicação pelo gás carbônico \\
Barotrauma dos pulmões & Intoxicação por outros gases \\
Barotrauma total & Apagamento \\
Barotrauma facial ou de máscara & \\
Barotrauma de roupa & \\
Barotrauma dental & \\
Bloqueio reverso & \multicolumn{1}{|c|}{ BIOFÍSICOS } \\
\hline EMBOLIA TRAUMÁTICA PELO AR & \\
& Doença descompressiva \\
\hline
\end{tabular}

Fonte: São Paulo, 2006, p. 61

Além dos efeitos diretos e indiretos da pressão no organismo dos mergulhadores, os perigos existentes no serviço de busca e recuperação subaquática do Corpo de Bombeiros são potencializados pelos riscos de contaminação química e biológica inerentes ao serviço executado, seja no resgate de cadáver em adiantado estado de decomposição, seja na recuperação de veículo submerso, cujo combustível e outros fluídos podem ocasionar acidentes (Figura 1).

Figura 1 - Recuperação de cadáver submerso 


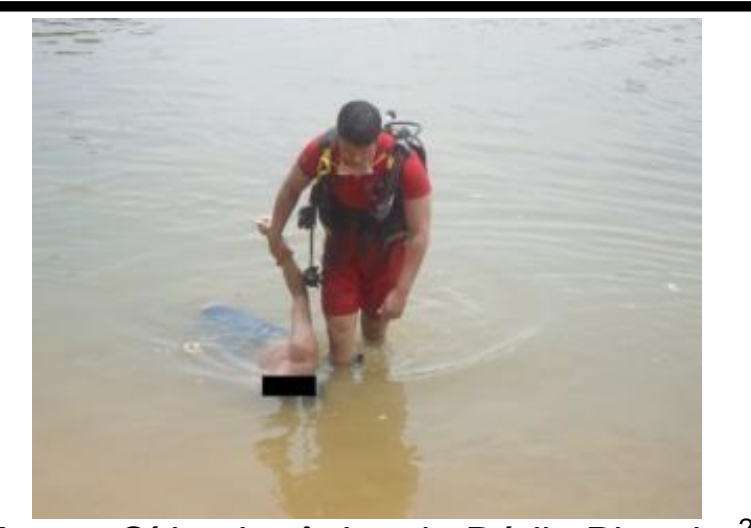

Fonte: Sítio eletrônico da Rádio Pioneira ${ }^{2}$

Cumpre observar que durante o resgate de cadáveres os riscos biológicos aos quais os mergulhadores bombeiros militares estão sujeitos ocorrem em razão dos fluídos corporais diluídos na água e que podem ocasionar diversas doenças, como febres, irritações, inflamações, hepatites, queimaduras químicas, dentre outras. Esclarecendo a questão, Glenn (2012, p. 90) enfatiza que: "[...] durante a recuperação o mergulhador é exposto a estes contaminantes. Mesmo em formas diluídas, devem ser considerados extremamente perigosos".

Vale lembrar que a recuperação de veículos também apresenta suas especificidades que, somadas aos efeitos da pressão, podem ser danosas à saúde e integridade dos mergulhadores (Figura 2). Além dos riscos próprios à aproximação e ao deslocamento de um objeto extremamente pesado, os veículos submersos frequentemente apresentam superfícies cortantes e perfurantes que demandam atenção esmerada do mergulhador. De modo análogo, o mergulhador deve estar atento às substâncias químicas existentes nos veículos, como combustíveis e óleos, que podem ser maléficos aos profissionais do mergulho. Diante do exposto, frisa-se que "[...] os veículos contêm produtos químicos que podem causar queimaduras químicas e erupções cutâneas tenazes. Estes podem ocorrer a partir da exposição aos

\footnotetext{
${ }^{2}$ Disponível em: http://www.radiopioneira.com.br/noticia/4028/sorriso\%3A-homem-morre-afogado-nasaguas- do-teles-pires. Acesso em: 15 nov. 2017.
} 


\section{Revista FLAMMAE}

Revista Científica do Corpo de Bombeiros Militar de Pernambuco

Artigo Publicado no Vol.06 N.16 - Edição Especial 2020 - ISSN 2359-4829

Versão on-line disponível em: $\underline{\text { http://www.revistaflammae.com }}$

fluídos ácidos e alcalinos que escoa do interior do veículo" (GLENN, 2012, p. 95).

Figura 2 - Recuperação de veículo submerso

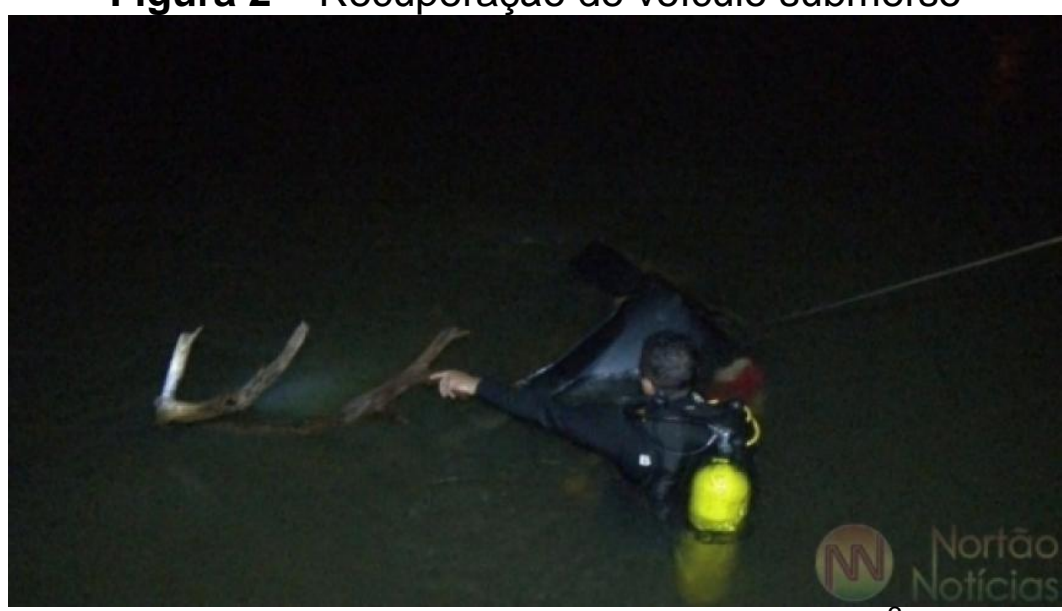

Fonte: Sítio eletrônico do Repórter $\mathrm{MT}^{3}$

\section{A INSALUBRIDADE E O ADICIONAL DE INSALUBRIDADE NO ORDENAMENTO JURÍDICO BRASILEIRO}

Para efeito de discussão, apresenta-se o conceito de insalubridade existente no ordenamento jurídico nacional. $O$ artigo 189 da Consolidação das Leis do Trabalho (CLT) define a insalubridade e estabelece os critérios para a sua definição nestes termos:

Serão consideradas atividades ou operações insalubres aquelas que, por sua natureza, condições ou métodos de trabalho, exponham os empregados a agentes nocivos à saúde, acima dos limites de tolerância fixados em razão da natureza e da intensidade do agente e do tempo de exposição aos seus efeitos (BRASIL, 1943).

Do exposto no artigo 189, pode-se deduzir que a insalubridade é a qualidade de insalubre, isto é, da capacidade que determinadas atividades ou

\footnotetext{
${ }^{3}$ Disponível em: http://www.reportermt.com.br/geral/mae-e-dois-filhos-morrem-afogados-em-mt-aposcarro- cair-em-rio/53714. Acesso em: 10 nov. 2017.
} 
operações possuem em originar doenças ou moléstias em virtude da exposição dos empregados a agentes nocivos. O trabalho insalubre seria, portanto, aquele realizado em condições não saudáveis que podem eventualmente causar uma doença.

A Constituição de 1988, no artigo $7^{\circ}, \mathrm{XXVIII}$, determinou, pela primeira vez, o adicional de periculosidade e insalubridade como direito dos trabalhadores, sendo grafado como "[...] adicional de remuneração para as atividades penosas, insalubres ou perigosas, na forma da lei" (BRASIL, 2016). $\mathrm{O}$ artigo em comento trata dos direitos sociais dos trabalhadores brasileiros e, como dito, assegurou aos que exercem atividades penosas, insalubres ou perigosas seu respectivo adicional de remuneração.

É oportuno esclarecer que a regulamentação do adicional de insalubridade para os trabalhadores celetistas está contemplada na própria CLT e na Norma Regulamentadora no 15 (NR-15) do extinto Ministério do Trabalho que trata dos limites de tolerância à exposição aos agentes danosos à saúde. No artigo 192, a CLT ordenou a percepção do adicional de insalubridade com a seguinte redação:

\footnotetext{
O exercício de trabalho em condições insalubres, acima dos limites de tolerância estabelecidos pelo Ministério do Trabalho, assegura a percepção de adicional respectivamente de $40 \%$ (quarenta por cento), $20 \%$ (vinte por cento) e 10\% (dez por cento) do saláriomínimo da região, segundo se classifiquem nos graus máximo, médio e mínimo (BRASIL, 1943).
}

A NR-15, por seu turno, traz em seu bojo os limites de tolerância à exposição aos agentes danosos ao organismo humano durante a vida laboral. Dentre as atividades classificadas como insalubres, a NR-15 estabeleceu em seu Anexo 6 o trabalho realizado sob condições hiperbáricas, compreendendo os executados sob ar comprimido e os submersos. No item 2.14.2 a NR-15 considerou a atividade de mergulho como insalubridade em grau máximo (BRASIL, 2017). 
Acompanhando o benefício determinado aos trabalhadores celetistas, a Lei $\mathrm{n}^{\circ}$ 8.112, de 11 de dezembro de 1990, estendeu o adicional de insalubridade aos servidores públicos civis da União, das autarquias e das fundações públicas federais. $\mathrm{O}$ artigo 61 da normativa em pauta determinou:

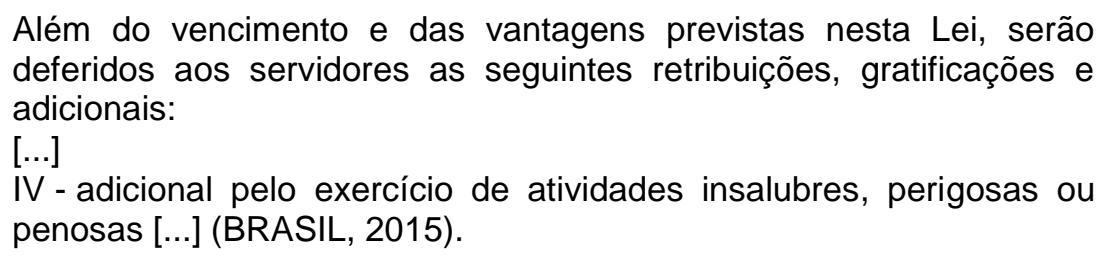

Em consequência, os servidores públicos federais também já asseguraram direito ao adicional de insalubridade pela Lei 8.112, esposando a respectiva vantagem pecuniária pelo exercício de atividades que resultem em danos à sua saúde.

\section{A COMPENSAÇÃO ORGÂNICA DAS FORÇAS ARMADAS}

As Forças Armadas, constituídas pela Marinha, Exército e Aeronáutica, instituições centenárias dotadas de estatutos e regulamentos próprios que servem de base para suas forças auxiliares nos estados (Polícias Militares e Corpos de Bombeiros Militares), igualmente reconheceram a necessidade de remunerar seus membros que apresentem desgaste orgânico resultante do desempenho continuado de atividades especiais por meio do Decreto ํㅡ 4.307, de 18 de julho de 2002 (BRASIL, 2002). Em contraposição ao texto celetista, que emprega o termo "adicional de insalubridade", a legislação das Forças Armadas utiliza a expressão "adicional de compensação orgânica" para os militares submetidos a situações de extremo perigo ou intenso esforço físico que gerem danos à sua saúde física e mental. $\mathrm{O}$ artigo $5^{\circ}$ do decreto em pauta assentou que:

O adicional de compensação orgânica é devido: 
Revista Científica do Corpo de Bombeiros Militar de Pernambuco

Artigo Publicado no Vol.06 N.16 - Edição Especial 2020 - ISSN 2359-4829

Versão on-line disponível em: $\underline{\text { http://www.revistaflammae.com }}$

I - durante a aprendizagem da respectiva atividade especial, a partir da data:

a) do primeiro exercício de vôo em aeronave militar;

b) do primeiro salto em pára-quedas de aeronave militar em vôo;

c) da primeira imersão em submarino;

d) do primeiro mergulho com escafandro ou com aparelho [...] (BRASIL, 2002, grifos nossos).

Acrescente-se que o adicional de compensação orgânica devido aos militares que executam atividades especiais danosas à saúde é regulamentado pela Medida Provisória no 2.215-10, de 31 de agosto de 2001 (BRASIL, 2001). Em seu Anexo II, Tabela V, são estabelecidos os valores percentuais que incidem sobre o soldo (Quadro 2).

Quadro 2 - Adicional de compensação orgânica das Forças Armadas

\begin{tabular}{|c|c|c|}
\hline SITUAÇÕES & $\begin{array}{l}\text { \% SOBRE O } \\
\text { SOLDO }\end{array}$ & FUNDAMENTO \\
\hline $\begin{array}{l}\text { Vôo em aeronave militar como } \\
\text { tripulante orgânico, observador } \\
\text { meteorológico, observador aéreo e } \\
\text { fotogramétrico }\end{array}$ & \multirow[t]{5}{*}{$-(-1)$} & \multirow{6}{*}{ Arts. $1^{\circ}$ e $3^{\circ}$} \\
\hline $\begin{array}{l}\text { Salto em paraquedas, cumprindo } \\
\text { missão militar }\end{array}$ & & \\
\hline $\begin{array}{l}\text { Imersão no exercício de funções } \\
\text { regulamentares a bordo de submarinos }\end{array}$ & & \\
\hline $\begin{array}{l}\text { Mergulho com escafandro ou com } \\
\text { aparelho }\end{array}$ & & \\
\hline Controle de tráfego aéreo & & \\
\hline $\begin{array}{l}\text { Trabalho com raio-x ou substâncias } \\
\text { radioativas }\end{array}$ & 10 & \\
\hline
\end{tabular}

Fonte: BRASIL, 2001

\section{O ADICIONAL DE INSALUBRIDADE E A LEGISLAÇÃO ESTADUAL DE MATO GROSSO}

A Constituição do Estado de Mato Grosso, ao tratar dos direitos e garantias fundamentais do povo mato-grossense, assegurou a imediata e plena efetividade de todos os direitos e garantias individuais e coletivas mencionadas 
na Constituição Federal. A par disso, o artigo 10 apresentou a seguinte redação:

\begin{abstract}
O Estado de Mato Grosso e seus Municípios assegurarão, pela lei e pelos atos dos agentes de seus Poderes, a imediata e plena efetividade de todos os direitos e garantias individuais $\mathbf{e}$ coletivas, além dos correspondentes deveres, mencionados na Constituição Federal, assim como qualquer outro decorrente do regime e dos princípios que ela adota, bem como daqueles constantes dos tratados internacionais em que a República Federativa do Brasil seja parte [...] (MATO GROSSO, 2014, grifos nossos).
\end{abstract}

Como se depreende da transcrição, a Constituição Estadual ratificou a aplicação dos direitos e garantias explicitados na Constituição Federal, dentre eles os elencados no artigo $7^{\circ}$, inciso XXIII, que trata do direito ao adicional de remuneração para as atividades insalubres.

A despeito desse dispositivo constitucional estadual, o legislador matogrossense, por ocasião da edição da Lei complementar no 555, de 29 de dezembro de 2014, que dispõe sobre o Estatuto dos Militares de Mato Grosso, não incluiu a previsão de compensação orgânica aos militares estaduais que executam atividades danosas à saúde na relação dos direitos, indenizações e vantagens. É o que se observa no artigo 63 apresentado na sequência:

São direitos, indenizações e vantagens eventuais dos militares estaduais, nas condições previstas nesta lei complementar e em legislação ou normas específicas e/ou peculiares:

I-Subsídio;

II - Promoção;

III - Ocupação de função correspondente ao posto ou graduação;

IV - Jornada de trabalho com descanso obrigatório;

V - Alimentação, assim entendida como as refeições fornecidas aos militares

em atividade;

VI - Férias;

VII - Remuneração do trabalho noturno, superior ao diurno;

VIII - Carteira de identidade funcional, de acordo com modelo regulamentar, que consigne os direitos e prerrogativas instituídas nesta lei complementar, para o exercício funcional, inclusive porte de arma;

IX - Afastamentos;

$\mathrm{X}$ - Licenças; 


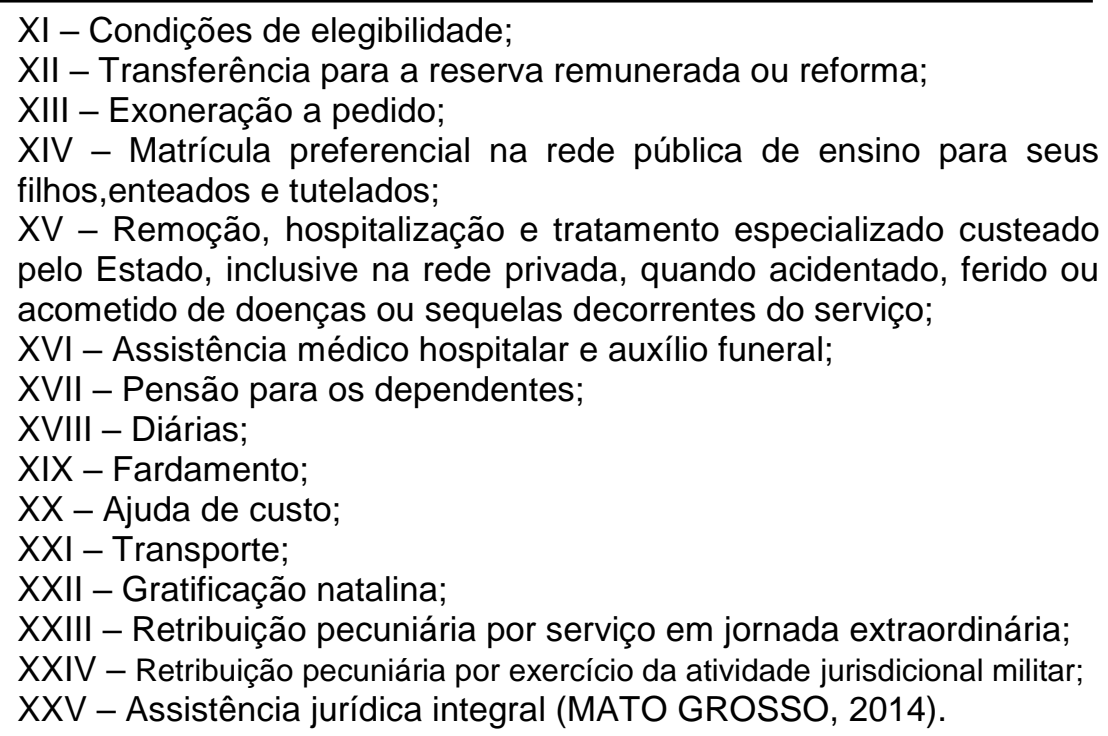

Analisando detidamente 0 artigo 63 da Lei complementar $n^{0}$ 555, percebe-se que o legislador estadual inicialmente entendeu ser necessário retribuir pecuniariamente os militares por serviço em jornada extraordinária e pelo serviço de atividade jurisdicional militar. Todavia, em setembro de 2019 o Tribunal de Justiça de Mato Grosso, em decisão colegiada, declarou a inconstitucionalidade de artigos do referido Estatuto revogando, dentre outros direitos, a percepção de retribuição pecuniária por serviço em jornada extraordinária e por exercício da atividade jurisdicional militar, além do adicional noturno e recebimento do auxílio-fardamento.

Uma ressalva, de capital importância, deve ser realizada: ainda que não tenha sido incluído no rol de direitos dos servidores militares estaduais, o Poder Executivo empreendeu esforços para regulamentar o adicional de insalubridade aos servidores estaduais por meio da Lei complementar ํㅡ 502, de 7 de agosto de 2013 (MATO GROSSO, 2013). Nesse contexto, o artigo $2^{\circ}$ da legislação em comento ajustou que:

Os servidores que trabalham com habitualidade em locais insalubres ou em contato permanente com substâncias tóxicas fazem jus ao adicional de insalubridade de acordo com o grau mínimo, médio ou máximo a que estejam expostos.

$\S 1^{\circ}$ Os valores do adicional de insalubridade ficam estabelecidos da seguinteforma: 
I - Grau mínimo de insalubridade: $\mathrm{R} \$ 100,00$ (cem reais);

II- Grau médio de insalubridade: $R \$ 185,00$ (cento e oitenta e cinco reais);

III - Grau máximo de insalubridade: $\mathrm{R} \$ 370,00$ (trezentos e setenta reais). $\S 2^{\circ} \mathrm{O}$ valor do adicional a que se refere este artigo será reajustado, anualmente, no mês de maio, com base no Índice Nacional de Preços ao Consumidor - INPC, apurado no período de janeiro a dezembro de exercício anterior (MATO GROSSO, 2013).

A Lei complementar em análise foi regulamentada com a edição do Manual de saúde e segurança no trabalho para os servidores da administração direta, autárquica e fundacional do poder executivo do estado de Mato Grosso (MSST), publicado no ano de 2015 e que estabeleceu, como indica a própria nomenclatura do título, as diretrizes da política estadual de saúde e segurança no trabalho (MATO GROSSO, 2015). O manual descreve, em detalhes, a estrutura necessária a ser implementada e as obrigações de cada órgão envolvido no desenvolvimento das diretrizes traçadas.

Observou-se que o MSST tratou da concessão do adicional de insalubridade aos servidores no âmbito do Poder Executivo estadual ao regulamentar, entre as páginas 90 a 205, a Lei Complementar no 502 utilizando como parâmetros os critérios da NR-15 do antigo Ministério do Trabalho. Verificou-se que a norma traz em seu bojo um modelo de Requerimento do Adicional de Insalubridade (RAl) que deve ser preenchido pelo servidor que pretenda receber o benefício.

É mister destacar que a concessão do adicional de insalubridade foi igualmente contemplado no Programa de Prevenção de Riscos Ambientais (PPRA), previsto no mesmo MSST, que detalha sua estrutura, desenvolvimento e discorre sobre o Laudo Técnico de Condições Ambientais de Trabalho (LTCAT) utilizado para mensurar a exposição aos agentes físicos, químicos, biológicos ou a associação de agentes prejudiciais à saúde ou à integridade física do servidor.

Em contraposição a essas considerações, os militares que realizam atividades de busca e recuperação subaquática do CBMMT não recebem o referido adicional de insalubridade estabelecido pela Lei complementar ํㅡㄴ 502 
e regulamentado pelo MSST. Nessa contenda, cumpre esclarecer que os motivos para a sonegação do benefício aos militares do CBMMT submetidos a riscos potenciais à saúde estão comentados nas próximas páginas desse artigo.

\section{METODOLOGIA}

Para os objetivos do presente estudo, foi pesquisado junto aos Corpos de Bombeiros Militares do Brasil, através de questionário com sete perguntas encaminhado entre os dias 13 e 17 de novembro de 2017 por meio da plataforma de pesquisas on-line Survey Monkey, aspectos relacionados à atividade de mergulho e ao pagamento do adicional de compensação orgânica. Concomitante ao envio dos questionários, entrevistou-se a gerente de saúde e segurança do trabalho da Secretaria Estadual de Gestão de Mato Grosso (SEGES-MT) no dia 13 de novembro de 2017, com vistas a obter o posicionamento oficial sobre a questão da insalubridade nas atividades desempenhadas pelos mergulhadores do CBMMT e tópicos relacionados à regulamentação da compensação orgânica desses profissionais. Esse colóquio, realizado na sede do órgão, se deu por meio de entrevista semiestruturada.

A análise proposta, e consequente compreensão da temática, oportunizou a realização de um mapeamento metódico sobre os estudos e marcos legais relacionados ao tema, que teve sua atenção restrita às Corporações de Bombeiros Militares. Realizada essa delimitação, verificou-se, contudo, que são escassas as pesquisas relacionadas ao assunto, persistindo diversas lacunas a serem preenchidas para que a temática possa ser devidamente contextualizada e compreendida.

\section{RESULTADOS E DISCUSSÕES}


Buscando problematizar a temática, ressalta-se que partiu-se da constatação da não existência do adicional de insalubridade ou de compensação orgânica aos mergulhadores do CBMMT que realizam o serviço de busca e recuperação. Essa realidade ocorre em discordância ao verificado no regime celetista, nas Forças Armadas e em outras Corporações de Bombeiros Militares brasileiras. A par disso, aprofundou-se os aspectos jurídicos e técnicos que caracterizam a insalubridade da atividade de mergulho, bem como a viabilidade de criação e implementação de uma retribuição pecuniária aos mergulhadores do estado de Mato Grosso.

Isso posto, reafirma-se que o mergulho é uma atividade de extremo perigo, sujeita a múltiplos efeitos diretos e indiretos que impactam a saúde dos mergulhadores. Seus riscos estão relacionados aos efeitos fisiológicos da pressão no organismo humano que podem desencadear acidentes e doenças. Comungando com essa premissa

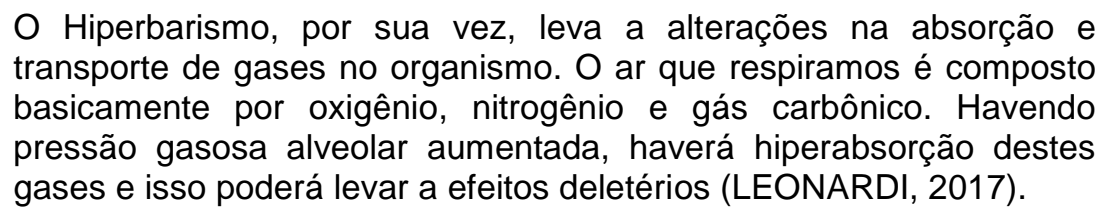

Outra particularidade a ser apontada é a de que além dos perigos inerentes aos trabalhos em ambientes hiperbáricos, constatou-se que o serviço de busca e recuperação subaquática do Corpo de Bombeiros Militar é permeado por outros riscos que potencializam a insalubridade da atividade. Não raro, é realizado em condições inóspitas e sob águas poluídas que sujeitam o mergulhador a uma série de doenças infectocontagiosas. Desdobrando essas considerações, a Norma de mergulho $n^{\circ}$ 1, editada pelo Corpo de Bombeiros Militar do estado do Espírito Santo, completa que:

Os riscos de ferimentos em objetos contundentes, cortantes e perfurantes provenientes da poluição, a facilidade de enrosco, falta de visibilidade e correnteza, possibilidade de contaminação, desonrientação, esgotamento do suprimento de gás, afogamento e 


\section{Revista FLAMMAE}

Revista Científica do Corpo de Bombeiros Militar de Pernambuco

Artigo Publicado no Vol.06 N.16 - Edição Especial 2020 - ISSN 2359-4829

Versão on-line disponível em: http://www.revistaflammae.com

perigos potenciais específicos do local de mergulho devem ser avaliados e tratados com atenção e cuidado já que são uma constante durante o serviço (ESPÍRITO SANTO, 2015).

Desde já cumpre observar que esses resultados foram confirmados pelas respostas dadas ao questionário enviado aos mergulhadores dos Corpos de Bombeiros Militares. $\mathrm{Na}$ investigação, obteve-se resposta de 23 das 27 corporações existentes no país, totalizando 84 questionários preenchidos (Gráfico 1). Esses relatos permitiram traçar um panorama das características da atividade de busca e recuperação subaquática, bem como aspectos relacionados ao adicional de compensação orgânica em cada corporação.

\section{Gráfico 1 - Corpos de Bombeiros Militares pelo Brasil que responderam ao} questionário

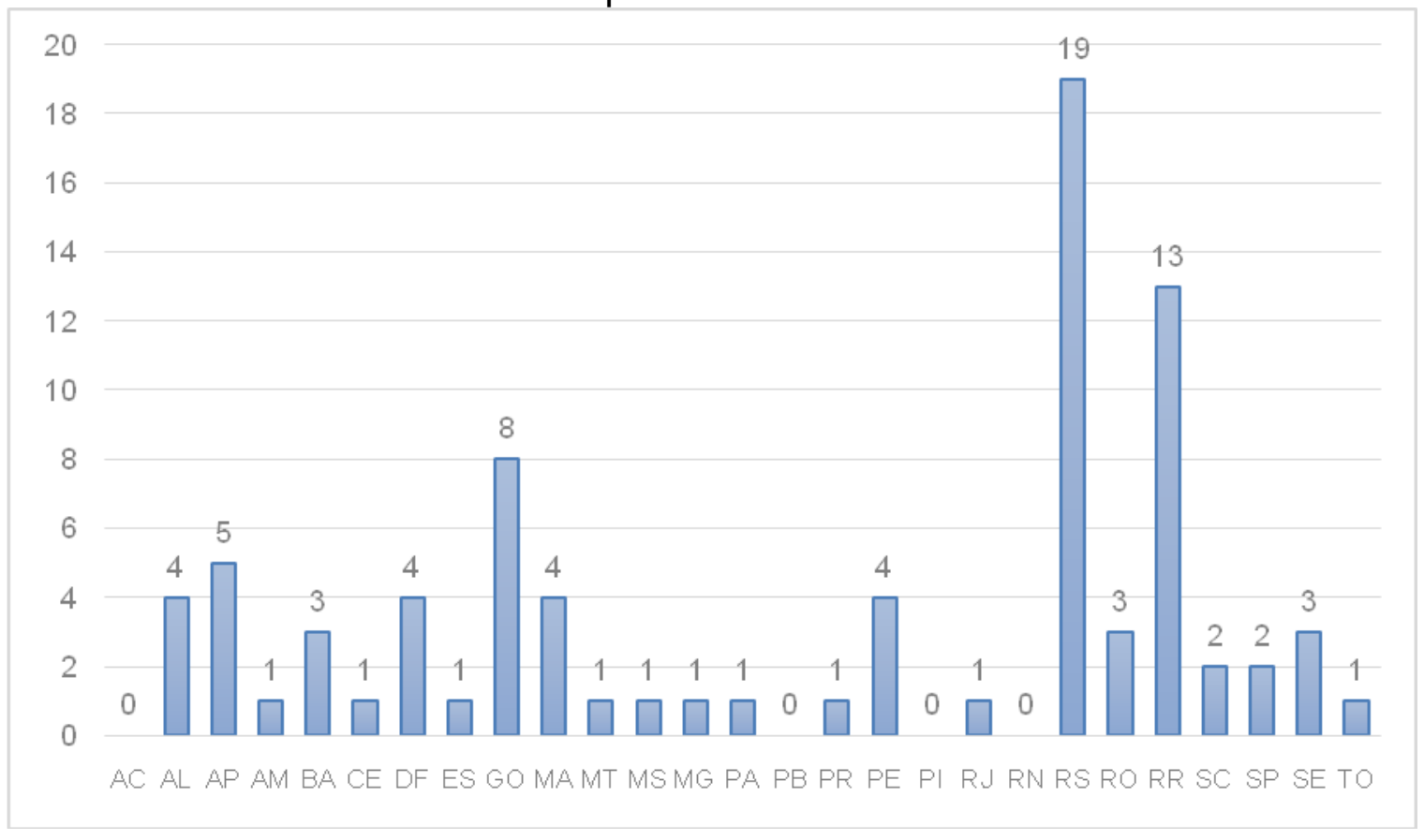

Fonte: Elaboração do autor

A incidência de acidentes/doenças relacionadas ao atendimento de ocorrências subaquáticas foi um dos pontos diagnosticados no questionário em pauta. Os resultados dessa inquirição podem ser visualizados no Gráfico 2. 
Gráfico 2 - Na sua corporação já houve casos de acidente/doença ocasionada em virtude do atendimento de ocorrência subaquática?

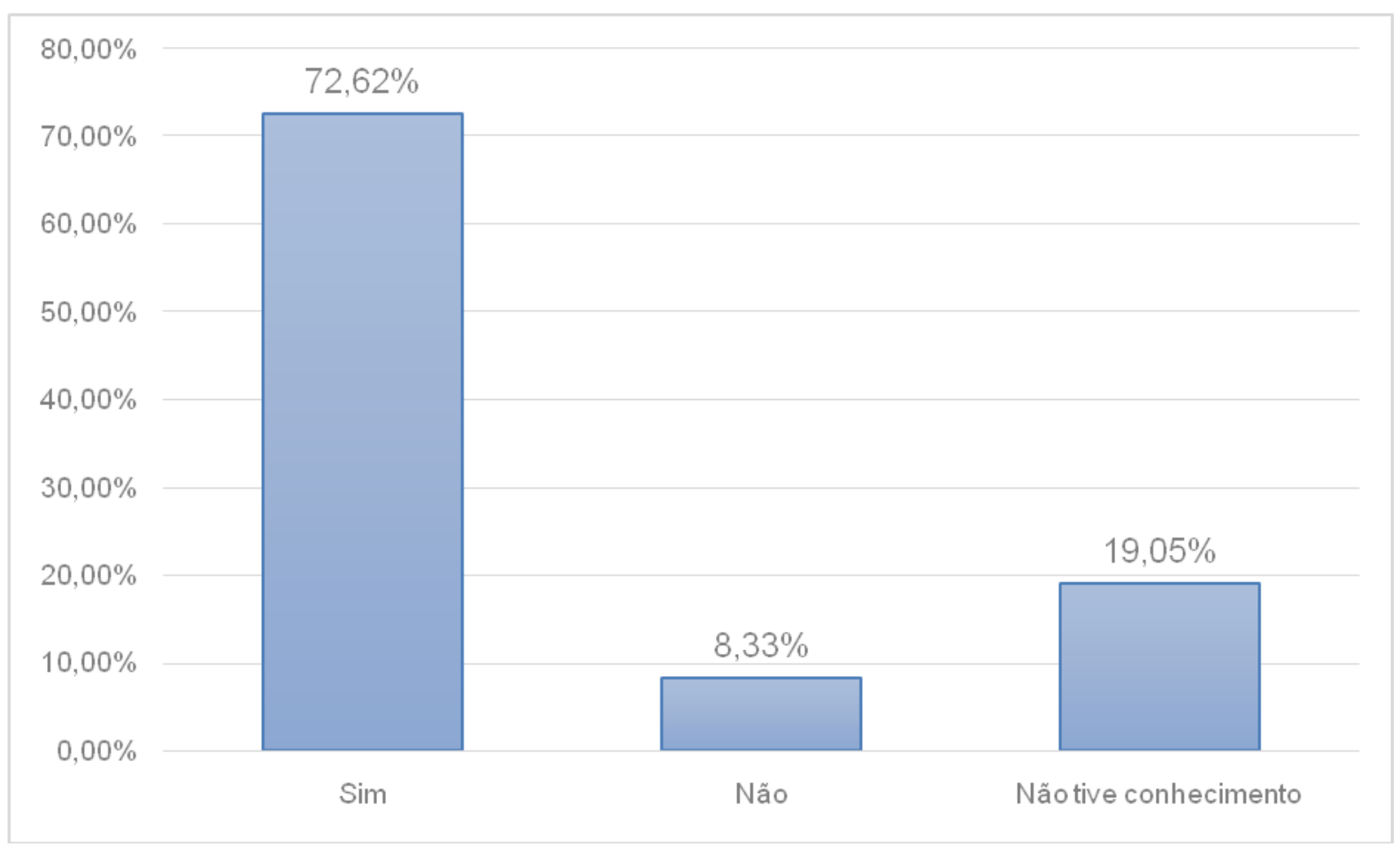

Fonte: Elaboração do autor

Analisando o Gráfico 2, observa-se que relatos de acidentes/doenças resultantes de ocorrência subaquática foram reportados por $72,62 \%$ dos que responderam a pesquisa, enquanto $8,33 \%$ declararam não ter conhecimento de tais casos. Diante desse quadro, reitera-se que a atividade de mergulho impacta diretamente os mergulhadores pelo elevado índice de acidentes e doenças, razão pela qual se invoca uma compensação aos mergulhadores.

O terceiro tópico do questionário indagou sobre a ocorrência de casos nos quais o mergulhador teve que empregar recursos próprios no tratamento de acidente/doença resultante do atendimento de incidentes subaquáticos. $O$ resultado está exposto no Gráfico 3. 


\section{Revista FLAMMAE}

Revista Científica do Corpo de Bombeiros Militar de Pernambuco

Artigo Publicado no Vol.06 N.16 - Edição Especial 2020 - ISSN 2359-4829

Versão on-line disponível em: http://www.revistaflammae.com

\section{Gráfico 3 - Na sua corporação já houve casos de algum mergulhador ter que utilizar de recursos próprios para tratar de acidente/doença ocasionada pelo atendimento de ocorrência subaquática?}

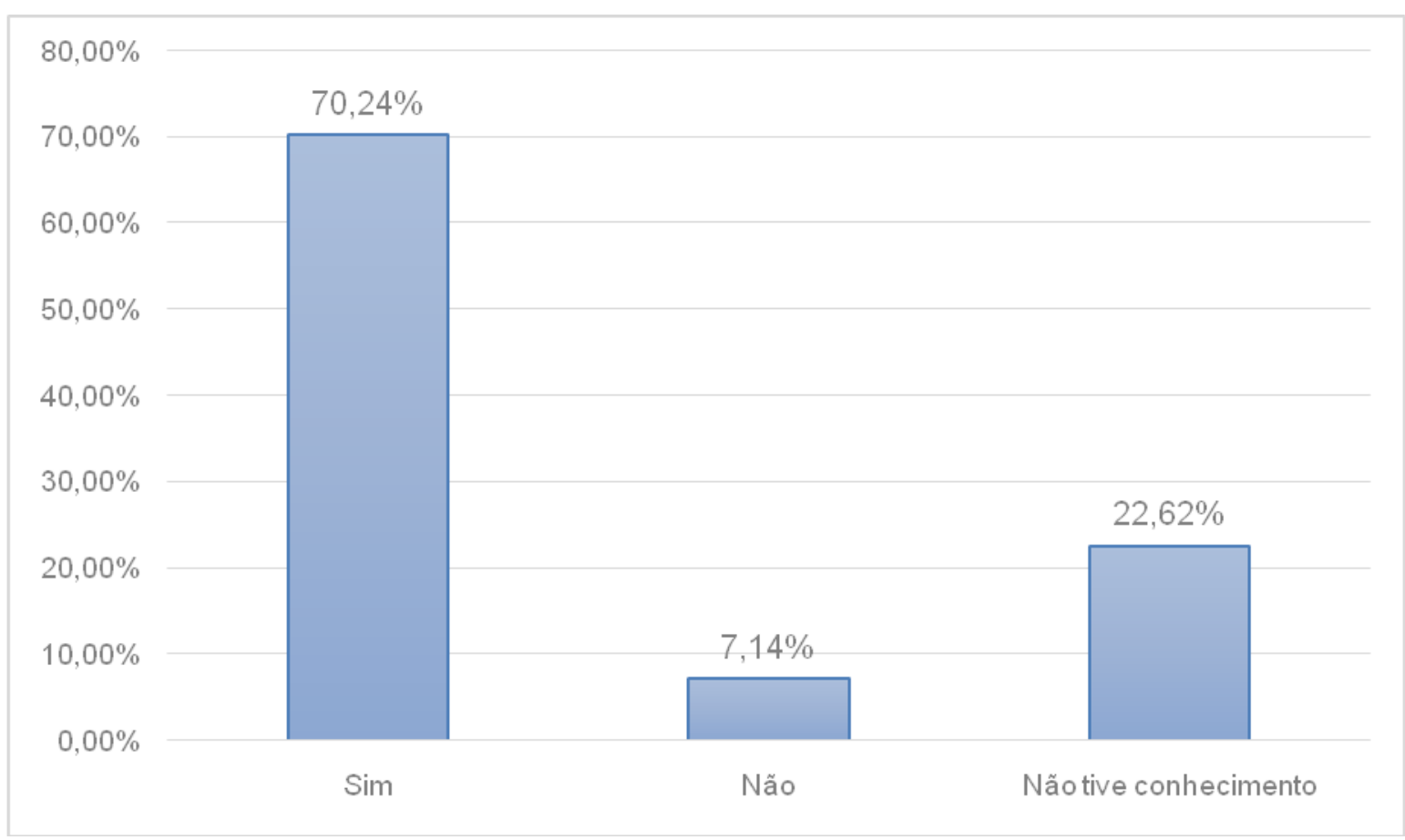

Fonte: Elaboração do autor

Uma análise do Gráfico 3 revela que 70,24\% dos 84 respondentes declararam a ocorrência de casos nos quais o mergulhador teve que arcar, às suas expensas, com o tratamento de acidente/doença, enquanto 22,62\% manifestaram não ter conhecimento de tais casos e 7,14\% refutaram a existência desse tipo de registro.

Com base nessas respostas, depreende-se que a assistência médica preventiva oficial apresenta falhas na oferta de proteção a esses profissionais. Sendo assim, não deixa de ser mais uma evidência a ratificar o pressuposto aqui adotado: da necessidade do pagamento de uma compensação aos mergulhadores que, conforme majoritariamente apontado nas respostas, se utilizam de recursos particulares no tratamento de acidentes/doenças resultantes do cumprimento de missão subaquática. 
O quarto item do questionário procurou verificar quais Corporações de Bombeiros Militares no Brasil já instituíram a concessão do adicional de compensação orgânica. Levantou-se que das 23 corporações que responderam ao questionário, duas já outorgam 0 adicional aos seus mergulhadores pelo exercício de atividade em ambiente hiperbárico. São elas: Corpo de Bombeiros Militar do Amapá e Corpo de Bombeiros Militar de Rondônia.

A quinta questão foi direcionada ao levantamento da legislação que regulamentou os referidos adicionais de compensação orgânica nos Corpos de Bombeiros voltados para a atividade de mergulho. No que se reporta ao Corpo de Bombeiros Militar do Estado de Rondônia, tal se deu por meio da Lei no 1.063, de 10 de abril de 2002, que estabeleceu o adicional da seguinte forma:

\footnotetext{
Art. 19. O Adicional de Compensação Orgânica, no valor correspondente a $8,081 \%$ (oito vírgula zero oitenta e um por cento) do soldo do Militar do Estado, é destinado a compensar os desgastes orgânicos consequentes dos danos psicossomáticos, resultantes do desempenho continuado das atividades especiais ou insalubres seguintes:

I - Mergulho com escafandro ou aparelho;

II - Contato constante com substancia tóxica ou radioativa; e

III - Trabalho com adestramento e acompanhamento de animais (RONDÔNIA, 2002, grifos nossos).
}

Quanto ao Amapá, o Estado criou uma lei específica para tratar da compensação orgânica aos mergulhadores bombeiros militares de forma a indenizá-los pelos danos sofridos. Trata-se da Lei ordinária ํำ1513, de 21 de setembro de 2010, que tem como redação:

Art. 1 Fica o Poder Executivo autorizado a executar a criação do Adicional de Compensação Orgânica, para os profissionais do Corpo de Bombeiros Militar do Estado do Amapá, que desenvolvem atividades hiperbáricas em operações de busca e salvamento.

[...]

Art. 4ํ $O$ valor dessa indenização será de $\mathbf{R} \$ 1.420,00$ (um mil, quatrocentos e vinte reais), reajustado a cada 2 (dois) anos, de acordo com o índice de aumento dado aos servidores públicos, acumulados no período (AMAPÁ, 2010, grifos nossos). 


\section{Revista FLAMMAE}

Revista Científica do Corpo de Bombeiros Militar de Pernambuco

Artigo Publicado no Vol.06 N.16 - Edição Especial 2020 - ISSN 2359-4829

Versão on-line disponível em: $\underline{\text { http://www.revistaflammae.com }}$

Retomando o fio da meada, a sexta pergunta do questionário procurou conhecer a opinião dos participantes quanto à importância do adicional de compensação orgânica na atividade de mergulho bombeiro militar. As respostas estão condensadas no Gráfico 4.

Gráfico 4 - Na sua opinião, qual a importância da compensação orgânica na atividade de mergulho do Corpo de Bombeiros Militar?

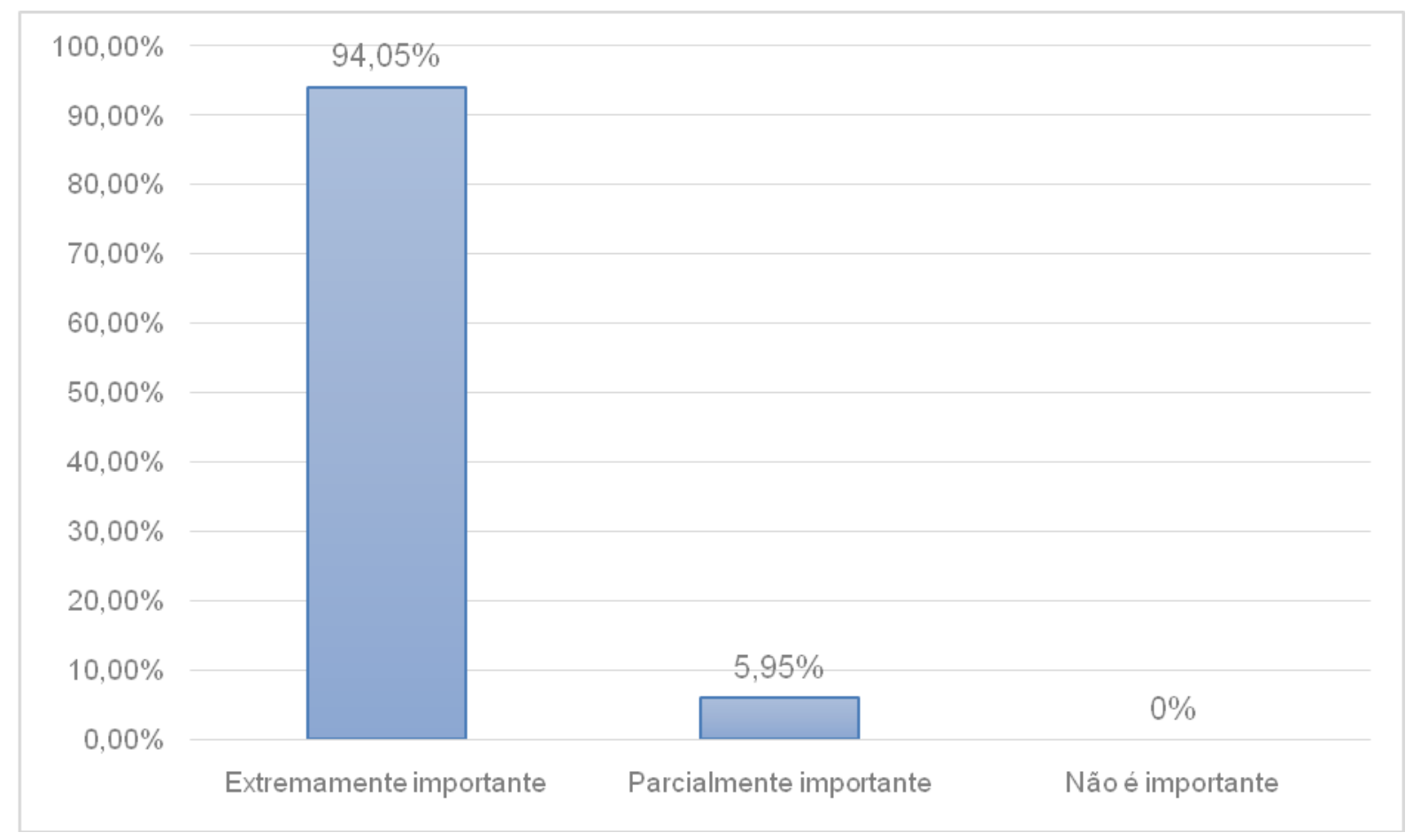

Fonte: Elaboração do autor

Os dados expostos no Gráfico 4 demonstram que o adicional para a atividade de mergulho é de extrema importância para 94,05\% dos respondentes e parcialmente importante para outros 5,95\%. Tal resultado denota uma sensibilização da categoria sobre a necessidade da criação do adicional de compensação orgânica para a atividade de mergulho bombeiro militar, a despeito dessa sensibilização não ter se traduzido em campanhas e lutas que implementassem a vantagem pecuniária na maioria esmagadora dos estados. 
Por fim, a sétima questão foi direcionada à averiguação dos motivos pelos quais, na ótica dos mergulhadores, justifica-se a criação do adicional de compensação orgânica na atividade de mergulho bombeiro militar. Nessa diretriz, reproduz-se o depoimento transcrito na sequência:

Como o nome diz, tal gratificação visa compensar o desgaste orgânico o qual é exposto o MG dos Corpos de Bombeiros. Exposição do corpo à águas contaminadas, ao risco de objetos e substâncias nocivas ao organismo, condições hiperbáricas. Contato direto com cadáveres e resíduos biológicos dos mesmos. Exposição do sistema respiratório a fontes de ar não naturais, que não sendo bem tratadas, potencializam os riscos (Entrevistado 1, grifos nossos).

Ponto de vista semelhante foi expresso por outro entrevistado nestes termos:

A atividade de mergulho, além do risco atinente a ela em virtude do tipo de serviço desempenhado no mergulho dos corpos de bombeiros, pode ocasionar uma série de danos psicossomáticos ao indivíduo submetido a trabalhos sob diferenciação de pressão que podem acarretar doenças para o resto da vida do indivíduo. Portanto, o adicional de compensação orgânica nada mais é que a devida 'recompensa' por tais profissionais se submeterem ao trabalho em condições altamente perigosas à saúde (Entrevistado 2, grifos nossos).

A par do que se comentou nesses últimos parágrafos, reafirma-se que a insalubridade e o adicional de insalubridade possuem previsão legal na Constituição de 1988. Todavia, percebeu-se no texto constitucional dispositivos aparentemente conflitantes no que se refere à concessão do adicional de compensação orgânica aos mergulhadores do estado de Mato Grosso, posto que estes recebem sua remuneração via subsídio. Sob este viés de análise, a Constituição de 1988 estabeleceu que:

Art. 39. A União, os Estados, o Distrito Federal e os Municípios instituirão conselho de política de administração e remuneração de pessoal, integrado por servidores designados pelos respectivos Poderes.

$[\ldots]$ 
§ 4으 $\mathrm{O}$ membro de Poder, o detentor de mandato eletivo, os Ministros de Estado e os Secretários Estaduais e Municipais serão remunerados exclusivamente por subsídio fixado em parcela única, vedado o acréscimo de qualquer gratificação, adicional, abono, prêmio, verba de representação ou outra espécie remuneratória, obedecido, em qualquer caso, o disposto no art. 37, X e XI.

[...]

$\S 8^{\circ}$ A remuneração dos servidores públicos organizados em carreira

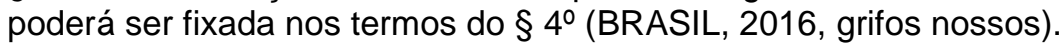

Assim, postula-se que o dispositivo citado pode induzir a administração pública a não querer indenizar seu servidor pelos trabalhos insalubres sob a justificativa de que sua remuneração ocorre por meio de subsídio. Em contraposição, entende-se que o adicional de insalubridade, enquanto direito social fundamental, não pode ser sonegado ao servidor que labore em atividades insalubres, posto que este nada mais é do que uma compensação financeira pelos danos cominados à saúde do trabalhador. Como tal, não deve estar incluído em sua remuneração, mas pagos à parte na folha de pagamento e também mencionados à parte nos contracheques. Reforçando essa ideia, Battu (2017) entende que: "[...] o referido adicional não pode ser negado ao servidor que labore em condições insalubres, este nada mais é que uma forma de compensação financeira pelo agente colocar sua saúde em risco durante seu período laboral'.

Seguindo esse raciocínio, levantou-se que os adicionais de insalubridade e periculosidade aos servidores remunerados por subsídio estão solidificados em diversos arcabouços jurídicos consultados. A título de ilustração, cite-se o caso dos servidores civis e militares do Poder Executivo do estado do Maranhão que recebem tais adicionais por força da Lei $n^{\circ} 306$, de 27 de novembro de 2007:

Art. 95-A. Os servidores remunerados por subsídio, que habitualmente trabalhem em locais insalubres, ou em contato permanente com substâncias tóxicas, radioativas, inflamáveis ou com eletricidade ou que causem danos à saúde, fazem jus ao adicional de insalubridade ou de periculosidade, com base em critérios definidos em regulamento (MARANHÃO, 2007). 
Supõe-se ter ficado claro que o adicional de insalubridade para os mergulhadores com vínculo celetista está regulamentado pela CLT e pela NR15 , razão pela qual recebem seus adicionais em grau máximo de insalubridade, consoante à classificação estabelecida pela própria legislação.

E a despeito de utilizar a nomenclatura "adicional de compensação", as Forças Armadas igualmente já regulamentaram e reconheceram a necessidade de ressarcir seus quadros militares pelo exercício de atividades especiais que resultem em danos à saúde, dentre os quais está o mergulho com escafandro e aparelho.

$\mathrm{Na}$ mesma perspectiva, a pesquisa demonstrou que algumas Corporações de Bombeiros Militares pelo país já compensam seus mergulhadores pelo exercício da atividade, de modo a repará-los financeiramente no enfrentamento de situações consideradas danosas à saúde pela sua própria natureza.

Os dados levantados confirmaram também que o estado de Mato Grosso ainda não regulamentou o adicional de compensação orgânica aos servidores militares que executam atividades danosas à saúde, motivo pelo qual a referida garantia não foi incluída no rol de direitos do Estatuto dos Militares promulgado no ano de 2014. Quaisquer que fossem, entretanto, as razões para essa exclusão entende-se ser plenamente justificável a criação de retribuição pecuniária de composição orgânica aos mergulhadores do CBMMT pelo exercício de atividades em ambientes hiperbáricos, posto serem ações de risco constante realizadas fora do ambiente natural, aumentando a possibilidade da ocorrência de graves acidentes ou fatalidades, além do desenvolvimento de doenças.

Um olhar mais apurado da questão permite perceber, porém, que o estado de Mato Grosso apresentou avanços significativos nos últimos anos na área da política de saúde e segurança do trabalho. Isso pode ser visualizado na edição da Lei complementar no 502, de 2013, e na publicação do MSST em 2015. Conforme ressaltado anteriormente, dentre as temáticas tratadas no 
manual está a definição de regras para a concessão do adicional de insalubridade aos servidores no âmbito do Poder Executivo estadual. Afirmar isso não significa descuidar do fato de que os mergulhadores militares não recebem, até a presente data, o referido adicional.

Nesse contexto é que se procurou conhecer o posicionamento oficial governamental através de entrevista realizada com a gerente de saúde e segurança do trabalho da SEGES-MT, Sandra Aparecida Donati Silvério, profissional responsável pela integridade física e mental dos servidores do Poder Executivo. Na ocasião, tomou-se conhecimento de conceitos relevantes para entendimento da política estadual de saúde e segurança do trabalho, especialmente no que se reporta ao reconhecimento da insalubridade do serviço de busca e recuperação subaquática do CBMMT. Para que fique mais claro, tal reconhecimento encontra embasamento da Lei complementar ํo 502 e passa pela estruturação da Comissão Local de Segurança no Trabalho (CLST) e emissão de um LTCAT. Nesse contexto é que o serviço de mergulho bombeiro militar seráadmitido como insalubre e os mergulhadores finalmente poderão receber o adicional de insalubridade previsto na legislação.

A gerente considerou também não haver impedimento legal que inviabilize a concessão do adicional de insalubridade aos mergulhadores bombeiros. Em sua percepção, o que existesão dificuldades para operacionalizar a estrutura necessária para a aplicação da Lei complementar no 502 ou a necessidade da criação de uma lei específica que regulamente e viabilize o recebimento do adicional aos mergulhadores do CBMMT. Declarou igualmente que o entendimento do Setor de Saúde e Segurança do Trabalho é de que toda atividade que ocasione danos à saúde deve ser compensada, independentemente da modalidade de remuneração, visto se tratar de indenização a ser paga separadamente enquanto 0 trabalhador estiver exercendo a atividade, cessando a remuneração após a interrupção dos trabalhos. 


\section{CONSIDERAÇÕES FINAIS}

A pesquisa analisou a possibilidade de pagamento de compensação orgânica aos mergulhadores do CBMMT que executam atividades de resgate às vítimas de afogamento, além da busca e recuperação de cadáveres, bens submersos e outras atividades de apoio. Entende-se que a compensação orgânica objetiva mitigar os efeitos nocivos das atividades especiais, notadamente dos riscos potenciais à saúde, além de manter os mergulhadores motivados a desempenhar trabalhos reconhecidamente importantes pela sociedade brasileira e mato-grossense.

O estudo identificou que apenas dois estados da federação realizam o pagamento de compensação orgânica aos mergulhadores militares dos Corpos de Bombeiros, a despeito do amparo legal consagrado em diversos corpos jurídicos para receber em seus vencimentos os acréscimos das atividades insalubres. No estado de Mato Grosso, os mergulhadores do CBMMT ainda não percebem a compensação orgânica, muito embora nos últimos anos tenham sido implantadas medidas abrindo a possibilidade desses profissionais serem agraciados com a devida compensação financeira. Evidenciou-se a necessidade de instrumentalizar a estrutura que permita operacionalizar a Lei complementar ํo 502, de 2013, ou a criação de lei específica voltada ao pagamento de compensação orgânica aos mergulhadores bombeiros militares.

$\mathrm{O}$ artigo não teve a pretensão de esgotar o assunto, posto a relevância da temática e escassez de trabalhos na área, mas antes fornecer subsídios para estudos futuros no intituito de autorizar o pagamento de compensação orgânica aos mergulhadores das diversas Corporações de Bombeiros Militares brasileiras. Obviamente, outros procedimentos de redução de risco devem ser implantados para permitir a melhoria da qualidade de vida desses profissionais, mas se mostra imperiosa a viabilização de tal direito remuneratório. Por fim, reitera-se a necessidade da introdução da referida compensação aos 


\section{Revista FLAMMAE}

Revista Científica do Corpo de Bombeiros Militar de Pernambuco

Artigo Publicado no Vol.06 N.16 - Edição Especial 2020 - ISSN 2359-4829

Versão on-line disponível em: http://www.revistaflammae.com

mergulhadores do CBMMT, profissionais que estão sujeitos a riscos diversificados no desempenho de suas funções sem receberem o adicional de compensação orgânica como ocorre nas demais profissões contempladas pelos adicionais de insalubridade e periculosidade.

\section{REFERÊNCIAS}

AMAPÁ. Lei ordinária n. 1513, de 21 de setembro de 2010. Autoriza o Poder Executivo a executar a criação do Adicional de Compensação Orgânica, para os profissionais do Corpo de Bombeiros Militar do Estado do Amapá, que desenvolvem atividades hiperbáricas, e dá outras providências. Macapá: Assembleia Legislativa, $2010 . \quad$ Disponível em: $<$ http://www.al.ap.gov.br/pagina.php?pg=buscar legislacao\&aba=legislacao\&submenu =listar legislacao\&especie documento $=\& a n o=\&$ pesquisa $=\& n$ doeB $=\& n$ leiB $=1513 \& d$ ata inicial $=\&$ data final $=\&$ orgao $B=\&$ autor $=\&$ legislaturaB $=>$. Acesso em: 18 out. 2017.

BATTU, T. M. M. Pagamento do adicional de insalubridade no subsídio. JurisWay, s. $\quad$ l., 27 mar. 2017. Disponível em: https://www.jurisway.org.br/v2/dhall.asp?id $d h=18784$. Acesso em: 30 out. 2017.

BRASIL. Constituição da República Federativa do Brasil de 1988. Brasília: Presidência da República, 2016. Disponível em: $<$ http://www.planalto.gov.br/ccivil 03/constituicao/constituicao.htm>. Acesso em: 20 nov. 2017.

BRASIL. Decreto no 4.307, de 18 de julho de 2002. Regulamenta a Medida Provisória no 2.215-10, de 31 de agosto de 2001, que dispõe sobre a reestruturação da remuneração dos militares das Forças Armadas, altera as Leis $n^{\circ}$ s 3.765, de 4 de maio de 1960, e 6.880, de 9 de dezembro de 1980, e dá outras providências. Brasília: Presidência da República, $2002 . \quad$ Disponível em: $<$ http://www.planalto.gov.br/ccivil 03/decreto/2002/d4307.htm>. Acesso em: 18 out. 2017. 
BRASIL. Decreto-Lei no 5.452, de 1ㅇ de maio de 1943. Aprova a Consolidação das Leis do Trabalho. Brasília: Presidência da República, 1943. Disponível em: <http://www.planalto.gov.br/ccivil 03/decreto-lei/del5452.htm>. Acesso em: 3 mar. 2011.

BRASIL. Lei no 8.112, de 11 de dezembro de 1990. Dispõe sobre o regime jurídico dos servidores públicos civis da União, das autarquias e das fundações públicas federais. Brasília: Presidência da República, 2015. Disponível em: $<$ http://www.planalto.gov.br/ccivil 03/leis//8112cons.htm>. Acesso em: 16 nov. 2017.

BRASIL. Medida provisória no 2.215-10, de 31 de agosto de 2001. Dispõe sobre a reestruturação da remuneração dos militares das Forças Armadas, altera as Leis $n^{0 s} 3.765$, de 4 de maio de 1960, e 6.880, de 9 de dezembro de 1980, e dá outras providências. Brasília: Presidência da República, 2001. Disponível em:<http://www.planalto.gov.br/ccivil 03/mpv/221510.htm>. Acesso em: 15 nov. 2017.

BRASIL. Ministério da Economia. Norma regulamentadora no 15 - atividades e operações insalubres. Brasília, 2017. Disponível em: $<$ http://trabalho.gov.br/seguranca-e-saude-no-trabalho/normatizacao/normasregulamentadoras/norma-regulamentadora-n-15-atividades-e-operacoesinsalubres >. Acesso em: 15 nov. 2017.

COSTA, J. R. M. Utilização de cães como ferramenta alternativa para auxiliar nas buscas de cadáver em operações subaquáticas no estado de Mato Grosso. Homens do Mato: revista científica de pesquisa em segurança pública, Cuiabá, v. 16, n. 2, p. 159-183, jan./jun. 2016. Disponível em: <file:///C:/Users/55659/Downloads/331-1006-1-PB\%20(1).pdf>. Acesso em: 15 nov. 2017.

ESPÍRITO SANTO. Corpo de Bombeiros Militar. Norma de Mergulho no 01. NORMERG. Vitória: Diretoria de Operações, 2015.

GLENN, M. Mergulhador ERD I: manual de operações. Flórida, EUA: International Training, 2012. 
LEONARDI, A. Fisiologia do mergulho. Grupo de mergulho Planeta Oceano, [Angra dos Reis], [201-]. Disponível em: $<$ http://www.planetaoceano.com/artigos/fisiologia/artigo fisiologia do mergulho .htm>. Acesso em: 15 nov. 2017.

MARANHÃO. Lei no 306, de 27 de novembro de 2007. Dispõe sobre 0 reajuste do vencimento e do subsídio dos servidores civis e militares do Poder Executivo, altera dispositivos da Lei no 6.107, de 27 de julho de 1994, e dá outras providências. São Luís: Secretaria de Transparência e Controle, 2007. Disponível em:<http://stc.ma.gov.br/legisla-documento/?id=1929>. Acesso em: 10 nov. 2017.

MATO GROSSO. Constituição do estado de Mato Grosso: texto constitucional promulgado em 5 de outubro de 1989, com as alterações adotadas pelas emendas constitucionais № 01/1991 a 71/2014. Cuiabá: AL, 2014.

em: $<$ https://www.al.mt.gov.br/arquivos/legislacao/constituicao estadual.pdf $>$. Acesso em: 15 nov. 2017.

MATO GROSSO. Lei complementar no 502, de 7 de agosto de 2013. Dispõe sobre as políticas de Saúde e Segurança no Trabalho e normas gerais para concessão de adicional de insalubridade no âmbito do Poder Executivo do Estado de Mato Grosso. Cuiabá: Assembleia Legislativa, 2013. Disponível em: <file:///C:/Users/55659/Downloads/lc-502-2013.pdf>. Acesso em: 10 nov. 2017.

MATO GROSSO. Lei complementar no 555, de 29 de dezembro de 2014. Dispõe sobre o Estatuto dos Militares do Estado de Mato Grosso. Cuiabá: Assembleia Legislativa, 2014.2 Disponível em: <file:///C:/Users/55659/Downloads/lc-555-2014.pdf>. Acesso em: 10 nov. 2017.

MATO GROSSO. Secretaria de Estado de Gestão. Manual de saúde e segurança no trabalho para os servidores da administração direta, autárquica e fundacional do poder executivo do estado de Mato Grosso. Cuiabá: SEGES, 2015. Disponível em: 
$<$ http://www.gestao.mt.gov.br/images/gestao-de-

pessoas/arquivos/Manual de Saude e Seguranca Publicacao.pdf>. Acesso em: 20 nov. 2017.

RAMOS, A. M. Mergulho e os riscos de barotrauma pulmonar. Brasil Mergulho, [s.l.], 14 jun. 2004. Disponível em: $<$ https://www.brasilmergulho.com/mergulho-e-os-riscos-de-barotraumapulmonar/>. Acesso em: 20 out. 2011.

RONDÔNIA. Lei no 1.063, de 10 de abril de 2002. Dispõe sobre a remuneração dos integrantes da carreira de militares do estado, e dá outras providências. Porto Velho: Assembleia Legislativa, 2002. Disponível em: <https://sapl.al.ro.leg.br/norma/3040>. Acesso em: 15 nov. 2017.

SÃO PAULO (Estado). Corpo de Bombeiros da Polícia Militar. Manual de operações de mergulho. São Paulo: Corpo de Bombeiros : Polícia Militar : Governo do Estado de São Paulo, 2006. Coletânia de manuais técnicos de bombeiros, 27. Disponível

em: $<$ https://www.bombeiros.com.br/imagens/manuais/manual-27.pdf $>$. Acesso em: 8 nov. 2017. 